\title{
The role of experience in the development of social competencies
}

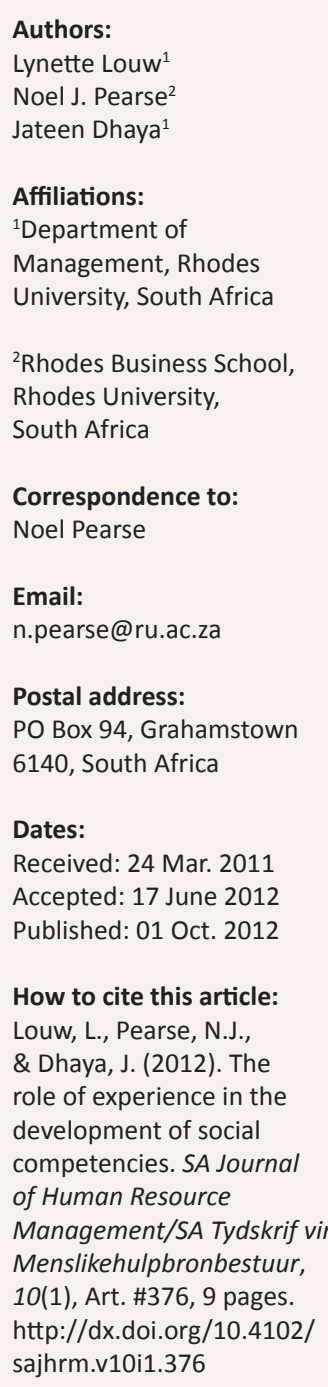

(C) 2012. The Authors. Licensee: AOSIS OpenJournals. This work is licensed under the Creative Commons Attribution License.
Orientation: The role of experience in the development of managers' social competencies has been analysed in this research.

Research purpose: The primary purpose of this study was to develop an understanding of the process through which experience contributed towards the development of service-oriented managers' social competencies.

Motivation for the study: Understanding the contribution of experiences to the development of competencies may have important implications for the selection and development of managers within service industries.

Research design, approach and method: Following a multiple case study design, face-to-face interviews with service-oriented managers were held, based on the critical incident technique. Data were analysed using the open coding procedures of grounded theory.

Main findings: Experience was found to contribute to the development of service-oriented managers' social competencies, through a process that established an awareness of unfamiliar social competencies, or a reinforcement of the effects of familiar effective social competencies.

Practical/managerial implications: The proposed process, the Social Competency Cache Development (SCCD) Process, is the practical outcome of the research which offers a tool to facilitate the development of social competencies through conscious leveraging of an individual's experiences.

Contribution/value add: The SCCD Process is recommended as a new avenue to leverage and thereby develop social competencies.

\section{Introduction}

The effective development of the social competencies of managers is critical to the success of enterprises operating within the hospitality industry. Competencies represent the synthesis of a variety of skills, technologies, and knowledge streams (Naquin \& Holton III, 2006) that generate a competitive advantage for an organisation (Jauhari, 2006). In general, the performance of managers is related to their possession and utilisation of competencies (Burgoyne, 1989 in Moore, Cheng \& Dainty, 2002; Murray, 2003; Stuart \& Lindsay, 1997). In the delivery of services in particular, social competencies are essential. This is because the service orientation in the hospitality industry is underpinned by service encounters, which are perceived to be 'social in nature, because the personal mode of delivery is intertwined with the provision of the tangible thing that initiated the encounter' (Chapman \& Lovell, 2006, p. 79). Previous research by Brophy and Kiely (2002), Kay and Russette (2000), Lockwood and Jones (1989, in Jauhari, 2006) and Tas (1988, in Jauhari, 2006), all view social competencies as essential managerial competencies required in the hospitality industry.

This research study is located in the hospitality industry with a specific focus on the bar and pub sector. According to the Restaurant Association of South Africa (2007, p. 2), a pub is an organisation that sells alcohol and light meals or snacks. The Tobacco Products Control Act 1993 (Act No. 83 of 1993) (Tshabalala-Msimang, 2000: Government Gazette Number 21610), which is the legislation controlling the smoking of tobacco products in public areas, defines bars and pubs as 'a public place where the primary business of the place is to sell alcoholic beverages to the general public, for consumption on the premises'. These definitions suggest that bars and pubs are primarily involved in the sale of alcoholic beverages to the general public for consumption on the premises. In rendering this service, managers of bars need to have social competencies, and should also be prepared to develop such skills.

It is therefore important for management practitioners and researchers alike to have an understanding of how these competencies would naturally develop, as a foundation for the 
deliberate development of these competencies through formalised organisational interventions. Competencies can be developed by both formal and informal learning methods (Svensson, Ellström \& Åberg, 2004). Kor (2003) suggests that managerial experience may shape managerial knowledge, confidence and competence, but few studies seem to have examined how competencies develop through experience. Cheetham and Chivers (2001) have investigated the informal learning methods of professionals. Paloniemi (2006) conducted research to examine the relationship of experience to the development of the job-competence of employees in the workplace. Mumford (1995) conducted research into the approaches that senior executives follow to learn from experience. Only a few studies have investigated informal learning methods of competency development and, thus, looking specifically within the hospitality industry, there is a dearth of research.

The main purpose of this study is to develop an understanding of the process through which their experience contributed towards the development of service-oriented managers' social competencies. The objectives of the study were, firstly, to identify the key social competencies that were required to deal with incidents that were critical to managerial success, in a socially challenging hospitality environment. Secondly, the objectives were to explore how these social competencies had developed through the individual interviewees' work-based and personal experiences. This research study is set in the South African hospitality industry and specifically in the bar and pub sectors of this industry. In these service-orientated environments bar managers must deal with many situations of a social nature which are particularly challenging.

The social competencies and the methods applied to develop such competencies will firstly be defined. Thereafter, experience and competency development will be explored, followed by the research design. Finally the findings and discussion will be presented, focusing on the Social Competency Cache Development (SCCD) Process, its implications and its potential application.

\section{Social competencies}

As mentioned above, competencies can be defined as a 'combination of observable and applied knowledge, skills and behaviours that create a competitive advantage for an organization' (Jauhari, 2006, p. 123). Brophy and Kiely (2002, p. 167) define them as 'the skills, knowledge, behaviours, and attitudes required to perform a role'. A competency 'therefore describes a feature of a person's ability to perform their job effectively' (Brophy \& Kiely, 2002, p. 167). According to Wickramasinghe and De Zoyza (2009), a competency is considered to be a measurable characteristic of a person that is related to his or her effective performance in a specific job, organisation or culture. These characteristics are defined in terms of behaviour, and because competencies are behavioural, they can be developed.

According to Katz (1955), who is a seminal author on the topic of managerial skills, in order to be effective, managers require technical skills, human skills and conceptual skills. Human skills are considered to be the equivalent of social skills or competencies.

Social competencies are considered as 'knowing and managing emotions in others', as well as the ability to work effectively with others (Cherniss \& Goleman, 2001, p. 29). Social competencies may also be defined as the 'ability to work with people' (Smit \& De J Cronjé, 2002, p. 17), and they include communication skills, social awareness, conflict resolution and motivating people (Cherniss \& Goleman, 2001; McKenna, 2004). For Bardzil and Slaski (2003), social competencies comprise communication skills, empathy and emotional labour. In their emotional intelligence framework Cherniss and Goleman (2001) highlight social competence as an element in the form of social awareness and relationship management. Social awareness can be explained as empathy, organisational awareness and service orientation (Ramo, Saris \& Boyatzis, 2009), whilst relationship management is evident in competencies such as influencing others, conflict management, teamwork and communication (Cherniss \& Goleman, 2001).

\section{The development of social competencies}

Competencies are developed by both formal and informal learning methods (Svensson et al., 2004). Formal learning methods are structured and include professional development programmes and educational programmes, whilst informal learning methods include the incidental experiences that individuals utilise to develop competencies (Cheetham \& Chivers, 2001). Garavan and McGuire (2001) are of the opinion that formal learning methods, such as individual training structures and workplace learning activities, are the dominant sources of competency development. It is important to recognise that whilst competency development may be facilitated through structured formal learning methods, such as formal education and training programmes, informal learning methods may also be utilised to develop competencies (Svensson et al., 2004). Incidental informal learning methods relate to the reference of experience to facilitate development (Cheetham \& Chivers, 2001).

The informal learning method of social competency development is highlighted in the realm of experiential learning. Experiential learning is founded on the concept that ideas are continuously being formed and reformed by life experiences (Cheetham \& Chivers, 2001). Thus, learning in the experiential sense seems to be a 'continuous process grounded in experience' (Cheetham \& Chivers, 2001, p. 256). This suggests that experiences represent a basis for learning and development. Experiential learning indicates that 'some things can be taught in a formal way, such as data', whilst other aspects 'have to be learned by experience' (Barnett, Chambers \& Longman, 1985, p. 4). More specifically, Morris's Continuum of Learning suggests that concrete knowledge is learned in a formal manner whereas social and interpersonal skills are learned through experience (Barnett et al., 1985). Hence, experience is a source of potential development. 


\section{The role of experience in developing competencies}

For the purpose of this research, an individual experience is defined as the process of successively construing the 'replications of events' (Kelly, 1955, p. 72). The combination of various individual experiences is then thought to represent the broader concept of experience. Firstly, this definition suggests that an experience is an active process (McKnight \& Sechrest, 2003). Accordingly, this process is perceived to be 'unceasing' in the sense that individuals are constantly being exposed to events (McKnight \& Sechrest, 2003, p. 433). Consequently, reconstruction of these events may be added to existing constructs of previous and related interpretations (Dale, 1998).

Secondly, for an experience to occur, an individual must have the opportunity to reconstruct and interpret events (McKnight \& Sechrest, 2003). McKnight and Sechrest (2003) give the example of a person who has slept during an earthquake. The person does not have the opportunity to reconstruct the events that took place whilst the earthquake occurred and therefore has not experienced the earthquake. The process of reflection facilitates the development of 'repertoires of solutions' (Cheetham \& Chivers, 1998, p. 267) and these are followed to reframe difficult problems into more comprehensible situations (Cheetham \& Chivers, 1998).

Thirdly, an experience, requires that individuals recognise events and reconstruct them into a broader and more extensive schema or framework, based on a series of events that have previously occurred, and then act in response to the reinterpretation of the event currently being experienced (McKnight \& Sechrest, 2003; Weil \& McGill, 1989). Repeated exposure to additional similar events allows individuals to constantly reinterpret events that are seen to be relevant in future, to refine and reconstruct their interpretations, which in turn leads to a change in behaviour for future tasks (Cheetham \& Chivers, 1998; McKnight \& Sechrest, 2003; Mumford, 1995).

Whilst a cognitive perspective has been adopted to explain competency development through experiences, behavioural approaches cannot be ignored. When behaviour has a rewarding consequence, it is reinforced and more likely to recur (Tennant, 1997). This implies that the knowledge gained from an experience, including the reinterpretation of previously held constructs, may contribute towards changes in individual behaviour, as this behaviour is reinforced and therefore repeated if the consequences of the behaviour are viewed as positive. In the context of this research study, positive or rewarding behaviour is seen as managerial behaviour that contributes to the successful development of social competencies. Success in displaying the developed social competencies is suggested to lead to improved employee and consumer satisfaction.

Paloniemi's (2006) research linked work experience to the construction of competence. However, the employees interviewed noted that their work experience alone was insufficient for the development of their competencies (Paloniemi, 2006), and emphasised the accumulation of a variety of experiences needed for development. In the context of this research study, 'experience' is deemed to refer to the collection of experiences that service-oriented managers have accumulated throughout their lives, and not only to the experiences gained in their role as managers. The rationale behind this is that experience occurs throughout one's life and, thus, to limit experience to that which occurs whilst employed as a manager would constrain the idea of accumulating experiences in a similar context, but in alternative roles, such as being a student, patron or a non-managerial employee.

Dale (1998) describes the cognitive aspects of competency development through Kolb's Learning Cycle, which describes how experiences are grasped and transformed. Once concrete experiences or abstract conceptualisations are grasped, they are reflected upon through a process of consideration to draw new implications based on that which was experienced (Kolb, Boyatzis \& Mainemelis, 2001). These cognitive processes, used to reinterpret constructs, are associated with short-term memory and long-term memory (Nicholas, 2003). The reflection process is employed by individuals to recover information from long-term memory into shortterm memory (Nicholas, 2003), based on its relevance to future behaviours and tasks (McKnight \& Sechrest, 2003). The retrieved information is then used comparatively (Dale, 1998), to facilitate the reconstruction of constructs.

Long-term memory is of particular importance as it is the repository of experiences, and is ultimately composed of explicit and implicit memory (Nicholas, 2003). In contrast to explicit memory, implicit memory cannot be consciously brought to mind (Nicholas, 2003). Implicit memory includes procedural memory, which represents the knowledge of skills or procedures (Nicholas, 2003). Procedural memories are typically acquired consciously and with practice and development of the competence, become less deliberate or consciously performed actions (Nicholas, 2003).

The Conscious Competence Learning Matrix (Thomson \& Van Solms, 2006) integrates both the cognitive and behavioural aspects associated with competency development that have been described above. This matrix links the levels of competence with degrees of consciousness (Leigh, 2003). It suggests that individuals proceed through four stages in developing their competencies or skills (Thomson \& Van Solms, 2006), namely 'Unconscious Incompetence', 'Conscious Incompetence', 'Conscious Competence' and finally 'Unconscious Competence'. The matrix highlights the role of cognitive ability, reflection and practice in moving through the four stages so that a competence becomes 'second nature' (Thomson \& Van Solms, 2006, p. 12). Furthermore, the transfer of competencies to the subconscious, as secondnature competencies, suggests that competency development is related to the repertoire of solutions built by experience. 
In summary, cognitive and behavioural learning theory offers a theoretical explanation for the development of social competencies through the accumulation of, and reflection on experiences. However, relatively few empirical studies have been conducted (see Cheetham \& Chivers, 2001; Kor, 2003; Mumford, 1995; Paloniemi, 2006) to examine its applicability to managerial competence development, and no studies were reported that examined the hospitality industry. Of interest in this study is the investigation of how social competencies have developed in bar managers, who operate in a particularly socially challenging part of the hospitality industry. The study seeks to investigate how these competencies develop through the accessing and processing of the individual's accumulated experiences, both work-based and personal.

\section{Research design \\ Research approach}

A qualitative approach is followed in this research study, and is phenomenological in nature as 'it is concerned with understanding human behaviour from the participant's own frame of reference' (Collis \& Hussey, 2003, p. 53). It recognises that the data is not presented in the form of external objective facts, but rather is a subjectively experienced construct that is mutually constructed during the social interaction between the researchers and the research participants (Mottier, 2005). It values a highly personal and local contextualist approach to knowledge, rather than one which seeks to generalise laws or principles across all situations (Aram \& Salipante, 2003). This approach is aligned with practical rationality theories, which value the investigation of how actors or practitioners constitute and enact the logic of their organisational practices, and views such accounts as valid (Sandberg \& Tsoukas, 2011).

This approach is appropriate, given that the purpose of the study is to understand the role of managers' personal experiences in the development of their social competencies. This research study employed a qualitative approach similar to that of Chell (2004) and Cope and Watts (2000). The aim of the Critical Incident Technique (CIT), as utilised by Chell (2004, p. 48), was to 'gain an understanding of the incident from the perspective of the individual, taking into account cognitive, affective and behavioural elements'.

\section{Research strategy}

A multiple case study method was employed in this research (Chell, 2004). The cases consisted of six managers working in bars or pubs in Grahamstown. Their ages ranged from 22 to 48 years of age. Five were male and one was female. All were White people, with the exception of one Black man. Most had received some formal management training and their years of experience as managers ranged from 18 months to 20 years.

\section{Research method}

\section{Research setting}

The bars and pubs that the managers worked in are public facilities located in Grahamstown, in close proximity to the university, and have a diverse range of clientele. The establishments typically opened for business before lunch and remained open until after midnight. During the day, they resembled restaurants with a quieter environment, but steady trade. In the evenings there was usually a brisk trade with a much larger client base consisting mainly of students, who came primarily to drink socially, rather than for a meal. Managers therefore must be able to adapt the way that they interact with these diverse clients, and typically face more challenging situations later in the night towards the end of a work shift.

\section{Entrée and establishing researcher roles}

Interviews were arranged and conducted by one of the authors. These were held when the manager was off duty.

\section{Sampling}

Purposive sampling (Welman, Kruger \& Mitchell, 2005) was applied to identify interviewees who had a minimum of one year's experience of managing a bar, and who were currently employed as managers in pubs or bars in Grahamstown. This ensured that the sample had sufficient working experience relevant to the study's focus on bars, and that they were acquainted with the Grahamstown context in this regard.

A total of six bar managers participated in the study. According to Ritchie and Lewis (2003, p. 83) qualitative samples are usually small in size as there is no requirement to 'determine statistically significant discriminatory variables'. Cope and Watts (2000) previously interviewed six respondents to explore the learning process of entrepreneurs in relation to their personal and business development in tandem, and indicated that the respondents provided a wide range of experiences and knowledge. Given the premise that the critical incident technique that was to be applied in this study would offer a 'rich source of information' (Chell, 2004, p. 56), it was anticipated when planning this study, that interviewing six participants in-depth should generate sufficient data for meaningful analysis.

\section{Data collection methods}

Semi-structured, in-depth interviews (Welman et al. 2005) were held with the six managers. The CIT (Cope \& Watts, 2000) was followed to frame the interviews. The CIT is defined as a 'qualitative interview procedure' that 'facilitates the investigation of significant occurrences', events or incidents that are identified by the respondent as being relevant to relate to the interviewer (Chell, 2004, p. 48). Flanagan (1954) originally developed and applied the CIT as a quantitative approach (Chell \& Pittaway, 1998) but, more recently, it has been applied in a wide range of disciplines (Gremler, 2004), and as a qualitative method. Chell (2004, p. 47) suggests that the CIT should be consulted to guide the conducting of interviews 'to capture the thought processes, frame of reference and the feelings about an incident or set of incidents, which have meaning for the respondent'. 


\section{Recording of data}

All interviews were recorded, transcribed verbatim, and then checked by one of the authors. The transcripts were used as a basis for analysis. Both the original recording and transcripts were stored for easy access at a later date, if further analysis, re-analysis or checking was required.

\section{Data analyses}

Data were analysed using the open coding procedures of grounded theory (Chell, 2004). 'Open coding' is the 'process of breaking down, examining, comparing, conceptualizing, and categorizing data' (Strauss \& Corbin, 1990, p. 61). In other words, open coding represents the portion of data analysis 'that pertains specifically to the naming and categorizing of phenomena through close examination of the data' (Strauss \& Corbin, 1990, p. 62).

\section{Strategies employed to ensure quality data}

The phenomenological approach emphasises 'the subjective aspects of human activity by focusing on the meaning, rather than measurement, of social phenomena' (Collis \& Hussey, 2003, p. 53). Consequently, qualitative approaches employ credibility, transferability, dependability, and confirmability (Riege, 2003) as quality benchmarks. These measures are seen as comparable to validity and reliability in quantitative research (Riege, 2003).

Credibility relates to the endorsement of research findings by the research participants (Riege, 2003). The credibility of the study was improved by giving feedback to participants of the analysed data and then receiving feedback from these interviewees on the degree to which their views had been captured accurately (Creswell, 1994). Corrections were made if required.

Merriam (1988, in Creswell, 1994, p. 158) notes that the 'intent of qualitative research is not to generalize findings, but to form a unique interpretation of events'. This research study is therefore not concerned with the generalisation of findings, but the transferability of the research findings. Transferability is parallel to the function of external validity and is achieved 'when the researcher shows similar or different findings of a phenomenon amongst similar or different respondents' (Riege, 2003, p. 81). The transferability of the research results was ensured through cross-case analysis, which was carried out in the data analysis phase of the research study to allow for comparisons between multiple cases (Miles \& Huberman, 1994, in Riege, 2003).

Dependability in qualitative research is equivalent to reliability in quantitative research (Riege, 2003). Dependability seeks to ensure 'stability and consistency in the process of inquiry' (Riege, 2003, p. 81). This was improved by ensuring that the researcher was aware of and safeguarded against his own theoretical position and biases (Hirschman, 1986). Additionally, consistency within the inquiry process was ensured by using a tape recorder to record all interview data (Riege, 2003).

Lastly, confirmability is concerned with the interpretation of data, 'ensuring that it is drawn in a logical and unprejudiced manner' (Riege, 2003, p. 81). Confirmability was improved through the retention of all transcribed material on a compact disc (CD) to facilitate reanalysis (Riege, 2003).

\section{Reporting}

The main themes generated through open coding are summarised, and then a more conceptual presentation of the findings is presented in the form of the SCCD. Unfortunately the length restriction of this article does not provide room to provide a more detailed presentation of the findings of the study that would have also incorporated thick descriptions.

\section{Findings Social competencies identified}

The participants in the study, in this case bar managers, displayed four categories of social competencies to deal effectively with the identified critical incidents and thereby fulfil their managerial duties. These are, namely:

- emotionally laden social competencies

- power-based social competencies

- dispute-handling social competencies

- information-handling social competencies.

Firstly, emotionally laden social competencies involved responses in which the participants related to others on an emotional level. This included showing concern and understanding, motivating others, and forming or strengthening relational partnerships. The participants utilised these competencies to address critical incidents relating to problematic employee behaviour, problematic consumer behaviour, service complaints by consumers, and work and personal problems faced by employees. Secondly, the power-based social competencies entailed the participants' interaction with others based on their positions of authority. This included asserting authority and issuing commands. The managers used their power-based social competencies to handle critical incidents concerning problematic employee behaviour, problematic consumer behaviour and service complaints by consumers. Disputehandling social competencies were implemented to deal with critical incidents relating to problematic employee behaviour and problematic consumer behaviour. These competencies involved the participants' interaction with others to resolve disputes. Thirdly, they employed their information-handling social competencies to address critical incidents pertaining to problematic employee behaviour, problematic consumer behaviour, service complaints by consumers, and problems that employees faced. The information-handling social competencies involved the participants' interaction with others to receive or give information. 


\section{Experiences that contributed towards the development of the identified social competencies}

The experiences recollected by the participants were either single specific experiences or multiple compounded experiences. Through the recollection of events that were considered single specific experiences, they implied that solitary events contributed to the development of social competencies. These solitary experiences related to events that they viewed as influential and therefore critical in their lives. Solitary experiences such as authoritative experiences, drunken dilemma experiences and supportive experiences were highlighted by the participants as the experiences that contributed towards the development of their social competencies.

The participants recalled experiences that occurred in a variety of contexts, including home, school, university, work and 'watering hole' contexts. This implies that social competencies may be developed through experiences that include more than work experiences, and ultimately suggests that experiences related to a broad range of contexts contribute to the development of social competencies. The experiences that the managers recollected were based on either their own past responses or the responses of other people whom they had observed.

The findings of this research study also imply that formal learning methods may be followed to develop social competencies. For example, one manager highlighted a formal camera-training course in the development of his social competencies, which suggests that formal learning methods also contributed to the development of social competencies.

\section{Social Competency Cache Development Process}

In further analysing how the variety of experiences noted above, were contributing to the development and honing of the social competencies, the SCCD Process was formulated as an explanatory model. As Figure 1 indicates, the SCCD Process is an ongoing process that focuses on the development of the social competencies located within the cache or reserve of responses referred to as the 'Personal Repertoire of Responses'. The social competencies represent responses to social situations. The Personal Repertoire of Responses, which is the storage point for social competencies, represents an accumulation of compounded and reinterpreted responses. Within the context of this research study, the personal repertoire of responses indicates an accumulation of effective responses which participants have developed through a variety of experiences. The experiences that the bar managers described occurred in home, school, university, employment or work, and 'watering hole' contexts. For instance, one respondent indicated how a teacher had instilled social etiquette in him by regularly instructing pupils to be the first to greet senior or elderly people, thereby teaching him the habit of initiating social contact. Another indicated that he had often counselled his friends when they had personal problems, whilst yet another described how a sales training course that used simulations that were filmed on camera and then reviewed, had made him acutely aware of his typical behavioural style and its impact, as well as training him in more effective ways to interact with customers. The Personal Repertoire of Responses therefore represents the pool of social competencies and experiences that the participants drew on when addressing social situations. This repertoire of responses was then applied in social situations to assist the participants to fulfil their managerial duties that were associated with ensuring employee and consumer satisfaction.

As illustrated in Figure 1, the SCCD Process encompasses several phases, including (1) The Situation phase, (2) An Assessment and Selection phase, (3) The Response phase, (4) The Results phase and (5) The Observation and Reflection phase.

The Situation phase of the SCCD Process refers to the critical incident or event that warrants a response. This relates to the social situation in which the bar participants would find themselves, or the event to which the participants were exposed. Such situations included an employee confronting the manager about his pay in front of other employees and clients, a customer who alleged that her belongings had been stolen whilst she was at the pub, and customers getting into an argument, or even a physical fight. Managers would then assess the situation and select an appropriate response from

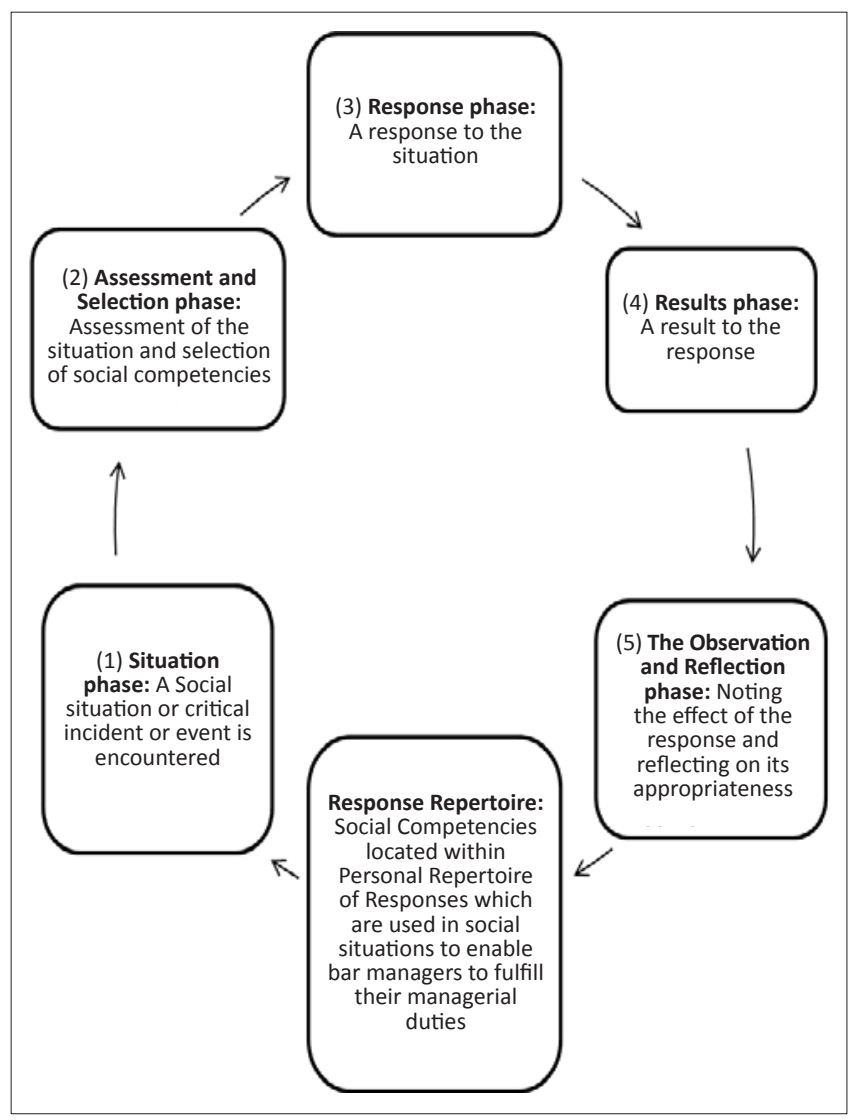

FIGURE 1: The Social Competency Cache Development Process. 
the social competencies located in their personal repertoire of responses. Examples of responses included clarifying the situation or expectations, solving problems by asserting authority, obtaining information, issuing instructions, explaining the consequences of actions, encouraging others by listening to them, giving them personal attention, and motivating them. The selected response is then physically implemented in the Response phase. The Results phase indicates the outcomes of implementing the selected responses. This was the successful resolution of the critical incident that the respondent had selected to talk about. Typical outcomes included strengthened relationships, motivated people, resolved disputes and an established common understanding. The Observation and Reflection phase is then executed to facilitate reinterpretation of previous responses and social competencies, by which the participants compared the outcomes of implementing the social competencies with the effectiveness of previous responses. These reinterpretations are then integrated with existing social competencies and compounded into the personal repertoire of responses. The process is continual in that the compounded personal repertoire of responses is followed to address subsequent social situations, and is continually shaped by the outcomes of implementing the reinterpreted responses and social competencies.

\section{Ethical considerations}

Research participants were informed of the voluntary nature of the research, and their consent to participate was obtained before the interview was conducted. The identity of the research participants was disguised by making use of pseudonyms rather than their real names, and the establishments where they were employed were kept confidential.

\section{Discussion}

The main purpose of this study was to develop an understanding of how personal experience contributed towards the development of the social competencies of service-oriented managers. Little empirical evidence exists in this area, and so it was anticipated that the findings would shed light on these developmental processes. In turn, understanding this process could contribute to the more effective selection of managers within the highly competitive service industries in general, and in the hospitality sector in particular, where the 'personal mode of delivery' (Chapman \& Lovell, 2006, p. 79) is particularly integral to the provision of quality service, and therefore business success. Furthermore, it could identify the developmental priorities of bar managers, which could be developed through formal job training, in combination with deliberately exposing them to certain types of situation.

From the analysis of the data, it would appear that bar managers required four categories of social competencies to be able to deal effectively with the identified critical incidents and thereby fulfil their managerial duties. These are, namely:

- emotionally laden social competencies

- power-based social competencies

- dispute-handling social competencies

- information-handling social competencies.

Whilst these competencies are also required by managers in other contexts (see for example Brophy \& Kiely, 2002; Chapman \& Lovell, 2006; Kay \& Russette, 2000; Murray, 2003; Stuart \& Lindsay, 1997), their significance to dealing with critical incidents that arise in this part of the hospitality industry, were clearly evident.

The findings indicated that participants recollected both significant and discrete single events, as well as multiple, compounded experiences. The recollection of a series of almost indistinguishable multiple compounded experiences would appear to strengthen the conclusion, offered by McKnight and Sechrest (2003), that repetitive exposures are required for the reinterpretation of constructs. Furthermore, the fact that experiences were compounded over time suggests that repeated exposure to an event may contribute to behavioural modifications, which is a requirement for the development of competencies (Civelli, 1998; Paloniemi, 2006; Tennant, 1997; Thomson \& Van Solms, 2006).

The fact that experiences based on the responses of other individuals were noted as contributing factors in the development of social competencies, suggests that interaction with other individuals may represent a key element in the development of social competencies. This would also be consistent with social learning theories such as vicarious learning (Bandura, 1977, 1995). Given the nature of social competencies in social situations, it is not surprising that the participants' observation of their social interactions with other individuals represented a source of learning.

In this study, the SCCD Process illustrates how experience could contribute to the development of the participants' personal repertoire of responses through a process of reflection. Consistent with the literature (Dale, 1998; Kolb et al., 2001; McKnight \& Sechrest, 2003; Tennant, 1997), respondents explained how their experiences and reflections seem to have assisted in developing their social competencies, by promoting the addition of new social competencies or through the reinterpretation and modification of existing social competencies.

The SCCD Process could therefore, possibly be utilised by service-oriented organisations, such as bars and pubs, as a framework for training that could leverage the unique experiences of managers. Essentially, the value of the SCCD Process is in encouraging conscious and intentional effort from individuals, to recognise the relevance of past experiences and to link them to the current situation, in order to facilitate an optimal response from them, or develop their social competencies. In other words, it forces individuals to consciously evaluate the potential value of past experiences. 


\section{Limitations of the study}

The limitations of this study are acknowledged, particularly in terms of its limited geographic context and the small number of respondents interviewed, whose experiences may prove to be atypical of pub and bar managers employed in other contexts. Further research could explore the applicability of the SCCD Process model to other bar managers and to other contexts within the service industry. The SCCD process itself needs to be critiqued and investigated in further depth. In particular, research is needed to explore the contextual and sub-conscious triggers which may prompt individuals to make the link between their past experiences and the current events to which they are exposed. Finally, there is a need to further investigate the relative contribution of, and interaction between, learning that arises from the experience of others versus personal experiences.

\section{Conclusion}

This study set out to develop an understanding of the process through which experience contributed towards the development of service-oriented managers' social competencies. The SCCD Process was developed to explain this contribution, describing a process that established an awareness of unfamiliar social competencies, or alternatively reinforced the effects of familiar effective social competencies and encouraged an intentional effort from individuals, to link past experiences to the current situation. Further research was recommended to explore the contextual and sub-conscious triggers which may prompt individuals to make this link, and to compare the effects of personal versus vicarious experience.

\section{Acknowledgements}

An earlier version of this paper was presented at the 22nd Annual Conference of the Southern African Institute of Management Scientists, hosted by Rhodes University in September 2010.

\section{Competing interests}

The authors declare that they have no financial or personal relationship(s) which may have inappropriately influenced them in writing this paper.

\section{Authors' contributions}

J.D. (Rhodes University) carried out the research as a Masters student under the supervision of N.J.P. (Rhodes University) and L.L. (Rhodes University). This manuscript was prepared by N.J.P. (Rhodes University) and L.L. (Rhodes University). All authors were at Rhodes University at the time of making their contribution.

\section{References}

Aram, J.D., \& Salipante, P.F. (2003). Bridging Scholarship in Management: Epistemological Reflections. British Journal of Management, 14, 189-205. http:// dx.doi.org/10.1111/1467-8551.00374
Bandura, A. (1977). Self-efficacy: Toward a unifying theory of behavioral change. Psychological Review, 2, 191-215. http://dx.doi.org/10.1037/0033295X.84.2.191, PMid:847061

Bandura, A. (1995). Self-Efficacy in Changing Societies. New York: Cambridge Press. http://dx.doi.org/10.1017/СB09780511527692

Bardzil, P., \& Slaski, M. (2003). Emotional intelligence: Fundamental competencies for enhanced service provision. Managing Service Quality, 13(2), 97-104. http:// dx.doi.org/10.1108/09604520310466789

Barnett, C., Chambers, R., \& Longman, K. (1985). Youth Education and Training Innovators - Learning from Experience: A training manual in personal effectiveness. Basingstoke: Macmillan Education.

Brophy, M., \& Kiely, T. (2002). Competencies: A new sector. Journal of European Industrial Training, 26(2/3/4), 165-176.

Chapman, A.J., \& Lovell, G. (2006). The competency model of hospitality service: Why it doesn't deliver. International Journal of Contemporary Hospitality Management, 18(1), 78-88. http://dx.doi.org/10.1108/09596110610642000

Cheetham, G., \& Chivers, G. (1998). The reflective (and competent) practitioner: A model of professional competence which seeks to harmonise the reflective practitioner and competence-based approaches. Journal of European Industrial Training, 22(7), 267-276. http://dx.doi.org/10.1108/03090599810230678

Cheetham, G., \& Chivers, G. (2001). How professionals learn in practice: An investigation of informal learning amongst people working in professions. Journal of European Industrial Training, 25(5), 247-292. http://dx.doi. org/10.1108/03090590110395870

Chell, E. (2004). Critical Incident Technique. In C. Cassell \& G. Symon (eds.). Essential Guide to Qualitative Methods in Organizational Research (pp. 45-60). London: Sage Publications.

Chell, E., \& Pittaway, L. (1998). A study of entrepreneurship in the restaurant and café industry: Exploratory work using the critical incident technique as a methodology. International Journal of Hospitality Management, 17(1), 23-32. http://dx.doi. org/10.1016/S0278-4319(98)00006-1

Cherniss, C., \& Goleman, D. (2001). The Emotionally Intelligent Workplace: How to Select for Measure, and Improve Emotional Intelligence in Individuals, Groups, and Organizations. San Francisco: Jossey-Bass.

Civelli, F. (1998). Personal competencies, organizational competencies, and employability. Industrial and Commercial Training, 30(2), 48-52. http://dx.doi. org/10.1108/00197859810207652

Collis, J., \& Hussey, R. (2003). Business Research: A practical guide for undergraduate and postgraduate students. (2nd edn.). Basingstoke: Palgrave Macmillan.

Cope, J., \& Watts, G. (2000). Learning by doing - An exploration of experience, critical incidents and reflection in entrepreneurial learning. International Journal of Entrepreneurial Behaviour and Research, 6(3), 104-124. http://dx.doi. org/10.1108/13552550010346208

Creswell, J.W. (1994). Research design: Qualitative and quantitative approaches. London: Sage Publications.

Dale, M. (1998). Developing Management Skills: Techniques for improving learning and performance. (2nd edn). London: Kogan Page Limited.

Flanagan, J.C. (1954). The Critical Incident Technique. Psychological Bulletin, 51(4), 327-358. http://dx.doi.org/10.1037/h0061470, PMid:13177800

Garavan, T.N., \& McGuire, D. (2001). Competencies and workplace learning: Some reflections on the rhetoric and the reality. Journal of Workplace Learning, 13(4), 144-163. http://dx.doi.org/10.1108/13665620110391097

Gremler, D.D. (2004). The Critical Incident Technique in Service Research. Journal of Social Research, 7(1), 65-89.

Hirschman, E.C. (1986). Humanist Inquiry in Marketing Research: Philosophy, method and criteria. Journal of Marketing Research, 23(3), 237-249. http://dx.doi. org/10.2307/3151482

Jauhari, V. (2006). Competencies for a career in the hospitality industry: An Indian perspective. International Journal of Contemporary Hospitality Management, 18(2), 123-134. http://dx.doi.org/10.1108/09596110610646673

Katz, R.L. (1955). Skills of an Effective Administrator. Harvard Business Review, 33(1), $33-42$.

Katz, R.L. (1986). Skills of an Effective Administrator. Harvard Business Review, 64(2), 198-198.

Kay, C., \& Russette, J. (2000). Hospitality-Management Competencies. Cornell Hotel and Restaurant Administration Quarterly, 41(2), 52-63. http://dx.doi. org/10.1177/001088040004100217

Kelly, G.A. (1955). The Psychology of Personal Constructs: Volume One. New York: W.W. Norton and Company Inc.

Kolb, D.A., Boyatzis, R.E., \& Mainemelis, C. (2001). Experiential Learning Theory: Previous research and new dimensions. In R.J. Sternberg \& L.F. Zhang (Eds.) Perspectives on Thinking, Learning, and Cognitive Styles, (pp. 227-247). Mahwah: Lawrence Erlbaum Associates.

Kor, Y.Y. (2003). Experience-based top management team competence and sustained growth. Organization Science, 14(6), 707-719. http://dx.doi.org/10.1287/ orsc.14.6.707.24867

Leigh, E. (2003). A Practitioner Researcher Perspective on Facilitating an Open, Infinite, Chaordic Simulation: Learning to Engage with Theory while Putting Myself into Practice. Unpublished Doctoral thesis, Sydney, University of Technology.

McKenna, S. (2004). Predispositions and context in the development of managerial skills. Journal of Management Development, 23(7), 664-677. http://dx.doi. org/10.1108/02621710410546669 
McKnight, P., \& Sechrest, L. (2003). The use and misuse of the term 'experience in contemporary psychology: A reanalysis of the experience-performance
relationship. Philosophical Psychology, 16(3), 431-460. http://dx.doi. relationship. Philosophical Psych
org/10.1080/0951508032000121814

Moore, D.R., Cheng, M., \& Dainty, A.R.J. (2002). Competence, competency and competencies: Performance assessment in organizations. Work Study, 51(6), 314-319. http://dx.doi.org/10.1108/00438020210441876

Mottier, V. (2005). The Interpretive Turn: History, Memory, and Storage in Qualitative Research. Forum: Qualitative Social Research, 6(2), Art 33

Mumford, A. (1995). Four Approaches to learning from experience. Industrial and Commercial Training, 27(8), 12-19. http://dx.doi. org/10.1108/00197859510791567

Murray, P. (2003). Organisational learning, competencies, and firm performance: Empirical observations. The Learning Organisation, 10(5), 305-316. http://dx.doi. org/10.1108/09696470310486656

Nicholas, L. (2003). Introduction to Psychology. Landsdowne: UCT Press.

Naquin, S.S., \& Holton III, E.F. (2006). Leadership and Managerial Competency Models: A simplified Process and Resulting Model. Advances in Developing Human Resources, 8(2), 144-166. http://dx.doi.org/10.1177/1523422305286152

Paloniemi, S. (2006). Experience, competence and workplace learning. Journal of Workplace Learning, 18(7/8), 439-450. http://dx.doi. org/10.1108/13665620610693006

Ramo, L.G., Saris, W.E., \& Boyatzis, R.E. (2009). The impact of social and emotional competencies on effectiveness of Spanish executives. Journal of Management Development, 28(9), 771-793. http://dx.doi.org/10.1108/02621710910987656

Restraurant Association of South Africa. (2007). The Gauteng Liquor Act 2003 and Regulations. Retrieved March 13, 2007, from http://www.restaurant.org. $\mathrm{za} / \mathrm{p}=$ gautengliquoract

Riege, A.M. (2003). Validity and reliability tests in a case study research: A literature review with 'hands-on' applications for each research phase. Qualitative Market Research: An International Journal, 6(2), 75-86.

Ritchie, J., \& Lewis, J. (2003). Qualitative Research Practice: A Guide for Social Science Students and Researchers. London: Sage Publications.
Sandberg, J., \& Tsoukas, H. (2011). Grasping the logic of practice: Theorizing through practical rationality. Academy of Management Review, 36(2), 338-360. http:// dx.doi.org/10.5465/AMR.2011.59330942

Smit, P.J., \& De J Cronjé, G.J. (2002). Management principles: A contemporary edition for Africa. (3rd edn.). Cape Town: Juta \& Co Ltd.

Strauss, A., \& Corbin, J. (1990). Basics of qualitative research: Grounded theory procedures and techniques. Newbury Park: Sage Publications.

Stuart, R., \& Lindsay, P. (1997). Beyond the frame of management competencies: Towards a contextually embedded framework of managerial competence in organizations. Journal of European Industrial Training, 21(1), 26-33. http://dx.doi. org/10.1108/03090599710156410

Svensson, L., Ellström, P.E., \& Åberg, C. (2004). Integrating formal and informal learning at Work. The Journal of Workplace Learning, 16(8), 479-491. http:// dx.doi.org/10.1108/13665620410566441

Tennant, M. (1997). Psychology and adult learning. (2nd edn.). London: Routledge.

Thomson, K.L., \& Van Solms, R. (2006). Towards an Information Security Competence Maturity Model. Computer Fraud and Security, 2006(5), 11-15. http://dx.doi. org/10.1016/S1361-3723(06)70356-6

Tshabalala-Msimang, M.E. (2000). Notice relating to smoking of tobacco products in public places, Government Gazette Number 21610, Notice Number 975. Sabinet Online, Government Gazette Database. [On-line]. Retrieved February 15, 2007, from $\mathrm{http}: / /$ search sabinet.co.za/WebZ/FETCH?sessionid=01-36111-522199638\& $\mathrm{re}$ $\mathrm{cno}=2 \&$ resultset=15\&format $=F \&$ next=html/t2/full.html\&bad=html/t2/error/ $\mathrm{Cno}=2 \&$ resultset=15\&format $=\mathrm{F} \&$ next $=\mathrm{html} / \mathrm{t} 2 /$ full.
badfetch.html\&\&entitytoprecno=2\&entitycurrecno $=2$

Weil, S.W., \& McGill, I. (1989). Making sense of experiential learning: Diversity in theory and practice. Milton Keynes: Open University Press.

Welman, J.C., Kruger, S.J., \& Mitchell, B. (2005). Research Methodology. (3rd edn.). Cape Town: Oxford University Press Southern Africa.

Wickramasinghe, V., \& De Zoyza, N. (2009). A comparative analysis of managerial competency needs across areas of functional specialisation. Journal of Management Development, 28(4), 344-360. http://dx.doi.org/10.1108/02621710910947371 